\title{
Effects of Environmental Conditions on High-Yield Magnetosome Production by Magnetospirillum gryphiswaldense MSR-1
}

\author{
Leila Hatami-Giklou Jajan ${ }^{1}$, Seyed Nezamedin Hosseini ${ }^{1}$, Masoud Ghorbani ${ }^{1}$, \\ Seyed Fazlollah Mousavi ${ }^{2}$, Behzad Ghareyazie ${ }^{3}$ and Mohsen Abolhassani ${ }^{4^{*}}$
}

\begin{abstract}
${ }^{1}$ Department of Research and Development, Research and Production Complex, Pasteur Institute of Iran, Karaj, Iran;
${ }^{2}$ Department of Microbiology, Pasteur Institute of Iran, Tehran, Iran; ${ }^{3}$ Agriculture Biotechnology Research Institute of Iran (ABRII), Agricultural Research, Education and Extension Organization (AREEO), Karaj, Iran;

${ }^{4}$ Hybridoma Lab., Department of immunology, Pasteur Institute of Iran, Tehran, Iran
\end{abstract}

\begin{abstract}
Background: Magnetotactic bacteria are a heterogeneous group of Gram-negative prokaryote cells that produce linear chains of magnetic particles called magnetosomes, intracellular organelles composed of magnetic iron particles. Many important applications have been defined for magnetic nanoparticles in biotechnology, such as cell separation applications, as well as acting as carriers of enzymes, antibodies, or anti-cancer drugs. Since the bacterial growth is difficult and the yield of magnetosome production is low, the application of magnetosome has not been developed on a commercial scale. Methods: Magnetospirillum gryphiswaldense strain MSR-1 was used in a modified current culture medium supplemented by different concentrations of oxygen, iron, carbon, and nitrogen, to increase the yield of magnetosomes. Results: Our improved MSR-1 culture medium increased magnetosome yield, magnetosome number per bacterial cell, magnetic response, and bacterial cell growth yield significantly. The yield of magnetosome increased approximately four times. The optimized culture medium containing $25 \mathrm{mM}$ of Na-pyruvate, $40 \mathrm{mM}$ of NaNO3, $200 \mu \mathrm{M}$ of ferrous sulfate, and 5-10 ppm of dissolved oxygen (DO) resulted in $186.67 \mathrm{mg}$ of magnetosome per liter of culture medium. The iron uptake increased significantly, and the magnetic response of the bacteria to the magnetic field was higher than threefold as compared to the previously reported procedures. Conclusion: This technique not only decreases the cultivation time but also reduces the production cost. In this modified method, the iron and DO are the major factors affecting the production of magnetosome by $M$. gryphiswaldense strain MSR-1. However, refining this technique will enable a further yield of magnetosome and cell density. DOI: 10.29252/ibj.23.3.209
\end{abstract}

Keywords: Conditioned culture medium, Magnetosomes, Magnetospirillum gryphiswaldense, MSR-1

Corresponding Author: Mohsen Abolhassani

Hybridoma Lab. Dept. of Immunology, Pasteur Institute of Iran, Tehran, Iran; E-mail: mabolhassani@yahoo.com

\section{INTROUDUCTION}

$\mathrm{O}$ ne of the most common Gram-negative prokaryotic cells with heterogeneous characteristics is magnetotactic bacteria being able to produce linear chains of bacterial magnetic particles (BacMPs) called magnetosomes ${ }^{[1]}$. BacMPs are intracellular organelles composed of magnetic iron particles surrounded individually by a phospholipid bilayer. The size of the magnetosome particles often varies within the species, ranging from 35 to $120 \mathrm{~nm}^{[2]}$. Magnetosomes mainly composed of magnetite $\left(\mathrm{Fe}_{3} \mathrm{O}_{4}\right)$ or greigite $\left(\mathrm{Fe}_{3} \mathrm{~S}_{4}\right)$ are assembled as one or more chain(s) depending on different elements and typically located close to the cytoplasmic membrane. Meanwhile, the number of magnetosomes in Magnetospirillum gryphiswaldense MSR-1 often differs with regard to the environmental conditions ${ }^{[3,4]}$. 
Magnetic bacteria have high biomineralization ability and are able to adjust themselves to new environmental conditions such as sever deprivation of metals ${ }^{[5]}$. It has been suggested that prokaryotes can be classified into biologically induced and biologically controlled mineralization based on their ability in synthesis of minerals $^{[6]}$.

Microbial reduction of metals and formation of magnetosomes within microorganisms in a marine environment were first discovered by Blakemore in $1975^{[7]}$. The biological production of the biomineralized magnetosomes is strictly controlled at the gene level, and the magnetosomes are normally formed in different sizes and shapes in magnetosome membrane ${ }^{[6]}$. Magnetosome synthesis has recently been proposed as a model for the formation of prokaryotic organelles and biomineralization ${ }^{[8,9]}$. Although the details of the mechanism for the synthesis of magnetosomes are not exactly clear, studies have shown that the formation of magnets is a cellular process that depends on several stages, including the separation of the internal membrane of the cell, the transfer of ions, the crystallization of magnetite within these vesicles, and the formation and arrangement of adult crystals as a linear structure of the cellular skeleton $^{[1,10]}$.

Unlike the chemical synthesis of other nanocrystals, magnetosomes are synthesized via unique features, including a perfect crystallographic appearance, a narrow and single magnetic domain in nanosize range with a permanent magnetization, and the formation of a biocompatible lipid bilayer around each mineral particle ${ }^{[2,11-13]}$, which bring about an exceptional importance in biotechnological applications of magnetic nanoparticles such as nuclear magnetic resonance, cell separation assays as drug carriers, and destruction of tumor cells by hyperthermia ${ }^{[14-18]}$. Since 1991, several applications including carriers for enzymes $^{[19]}$, nucleic acids ${ }^{[8,20]}$, and antibodies ${ }^{[19]}$ as well as anticancer drugs ${ }^{[8,9,21]}$ have been reported for bacterial magnetosomes. However, because of the difficulty in growing magnetotactic bacteria and the low-yield production of magnetosomes, these applications have not been extended to commercial scale $^{[10,13]}$. Various kinds of culture media such as the optimized flask medium (OFM), large-scale medium, magnetic spirillum growth medium, and optimized growth medium have been developed to fulfill the requirements of magnetotactic bacteria ${ }^{[11]}$. Adjustment of oxygen, temperature, and redox potential have been demonstrated to be remarkably effective in magnetosome production and magnetotactic bacterial yield in fed-batch flasks and bioreactors ${ }^{[11,12,22]}$. Moreover, most of the magnetotactic bacteria strains have been found to consume oxygen, ferric quinate, and nitrate as electron acceptors and use succinate or lactate, acetate, and nitrate as electron donors ${ }^{[11]}$. Culture medium optimization was very effective for high-yield cultivation of magnetosome, as it has previously been reported that at higher dissolved oxygen (DO) level, cell growth would be greater, but for higher yield of magnetosome, low DO concentrations are the prerequisite ${ }^{[23,24]}$. Thus, to resolve this situation, it is necessary to enhance DO to an optimum level by stirring the medium to increase the magnetotactic bacteria growth and allow the microbe to lower DO by the respiration process to an optimum level. Some of the important obstacles in the mass culture of magnetic bacteria are adjusting the oxygen level and optimizing the culture medium.

The main aim of this study was to investigate the effect of various concentrations of medium compounds, including oxygen, iron, carbon, and nitrogen to improve the growth of $M$. gryphiswaldense MSR-1 and to increase the yield of magnetosome.

\section{MATERIALS AND METHODS}

\section{Bacterial strain and culture}

M. gryphiswaldense MSR-1 was purchased from Leibniz-Institute, DSMZ-German Collection of Microorganisms and Cell Cultures (Germany) and cultured in the initial medium in a 7.5 -L fermentor (oxystate, FerMac, 310/60, UK). All chemicals (analytical grade) were procured from Merck (Germany).

\section{Initial medium preparation}

The initial culture medium was prepared with the Na-lactate medium as described previously ${ }^{[10]}$. Briefly, all medium components, except $\mathrm{K}_{2} \mathrm{HPO}_{4}$, were dissolved in $5.4 \mathrm{~L}$ of distilled water in a $7.5-\mathrm{L}$ fermentor and then autoclaved at $121{ }^{\circ} \mathrm{C}$ for $30 \mathrm{~min}$. $\mathrm{K}_{2} \mathrm{HPO}_{4}$ was dissolved in $200 \mathrm{ml}$ of distilled water and after sterilization, pumped into the fermentor before inoculation. Optimal culture condition was confirmed by adjusting the types and amounts of iron, nitrogen, and carbon sources. The growth of $M$. gryphiswaldense MSR-1 was evaluated using optical density (OD) at $400 \mathrm{~nm}$, by an ultraviolet-visible (UV-Vis) spectrophotometer (Lambda Bio35, Perkin Elmer, USA).

\section{Growth conditions}

Bacterial cells were cultured in a 7.5-L oxystate fermentor at $30{ }^{\circ} \mathrm{C}$ for 50 hours, and $\mathrm{pH}$ was maintained at 6.8 during cultivation by the nutrient solutions (ferric quinate, $6.5 \mathrm{~g}$; sodium pyruvate, 159 
$\mathrm{g}$; lactic acid, $52.6 \mathrm{~g} ; \mathrm{NaNO}_{3}$ per liter, $84.5 \mathrm{~g}$ ). Initial air flow and stirring rate were controlled at $0.5 \mathrm{~L} \mathrm{~min}-1$ and $100 \mathrm{rpm}$, respectively ${ }^{[12]}$.

\section{Preparation of optimized medium}

The OFM or modified OFM (MOFM) contained 0.1 $\mathrm{g}$ of $\mathrm{MgSO}_{4} .7 \mathrm{H}_{2} \mathrm{O}, 0.05 \mathrm{~g}$ of sodium thioglycolate, 0.1 $\mathrm{g}$ of yeast extract, $0.5 \mathrm{~g}$ of $\mathrm{K}_{2} \mathrm{HPO}_{4}, 5 \mathrm{ml}$ of mineral elixir, $200 \mu \mathrm{M}$ of ferrous sulfate, $40 \mathrm{mM}$ of $\mathrm{NaNO}_{3}$, and $25 \mathrm{mM}$ of $\mathrm{Na}$ pyruvate, per liter deionized water. The $\mathrm{pH}$ was adjusted to 6.8 with $\mathrm{NaOH}$. The inoculum used for the initiation of culture was grown by three sequential transfers at a ratio of $10 \%(\mathrm{v} / \mathrm{v})$ at 30 ${ }^{\circ} \mathrm{C}$ and agitated in a shaking incubator at $100 \mathrm{rpm}$ for $50 \mathrm{~h}$.

\section{Determination of growth and magnetite formation}

Cell growth was determined at OD $400 \mathrm{~nm}$. The average magnetic orientation of cell suspensions was assayed by an optical method as described previously $^{[25]}$. Briefly, bacterial cells were aligned at different angles relative to the light beam by means of an external magnetic field using a spectrophotometer (Hitachi U-2800, Japan). The ratio of the resulting maximum and minimum scattering intensities (magnetic response [Cmag]) was shown to be well correlated with the average number of magnetic particles and can be used for the semi-quantitative evaluation of magnetite formation ( $\mathrm{Cmag}=1$ corresponds approximately to 10 particles per cell).

\section{Isolation of magnetosomes}

M. gryphiswaldense cells (approximately $10 \mathrm{~g}$ of wet weight) was suspended in a 100-ml buffer containing $20 \mathrm{mM}$ of HEPES, $4 \mathrm{mM}$ of EDTA, $0.1 \mathrm{mM}$ of phenylmethylsulfonyl fluoride, $\mathrm{pH} 7.4$ and disrupted three times using an ultra homogenizer (GEA Niro Soavi, Germany). The suspension was then centrifuged at $680 \times \mathrm{g}$ for 10 minutes to remove the unbroken cells, and the cell debris and the supernatant were passed through a MACS magnetic separation column (Germany's Miltenyi Biotec). To bind the magnetic particles to the column matrix, the columns were placed between two Sa-Co-magnets generating a magnetic field gradient inside the column. The separation of magnetosome particles was completed at the time when there was no trace of black magnetosome-like particles in the cell extract after passage through the column. The attached magnetic particles to the column were rinsed with $50 \mathrm{ml}$ of 10 $\mathrm{mM}$ HEPES, $200 \mathrm{mM}$ of $\mathrm{NaCl}, \mathrm{pH} 7.4$ and subsequently with $100 \mathrm{ml}$ of $10 \mathrm{mM}$ HEPES, $\mathrm{pH} 7.4$, to eliminate electrostatically bound contamination. The column was then removed from the magnets, and magnetic particles were eluted from the column by flushing out with a 10-mM HEPES buffer. The magnetosome suspension was finally loaded on the top of a sucrose cushion (55\% [wt/wt] sucrose in $10 \mathrm{mM}$ HEPES, pH 7.4) and centrifuged in a swinging $50-\mathrm{ml}$ bucket rotor at $280,000 \times \mathrm{g}$ at $4{ }^{\circ} \mathrm{C}$ for 8 hours using an ultracentrifuge. The supernatant containing sucrose ingredient was removed, and the pelleted magnetosomes were suspended in 0.1-M PBS buffer $(\mathrm{pH} 7.4)$ and centrifuged at $11,000 \times \mathrm{g}$ at $4^{\circ} \mathrm{C}$ for 8 minutes, finally disrupted using an ultrasonic cell crusher $(300 \mathrm{~W})$ for $4 \mathrm{~s}$ with an interval of $8 \mathrm{~s}$ and repeated 80 times. Extracted magnetosomes were then absorbed to the bottom of the beaker using a magnetic field, and the cell debris was removed by discarding the supernatant. The magnetosomes were resuspended in $0.1 \mathrm{M}$ of PBS ( $\mathrm{pH} \mathrm{7.4)}$ and ultrasonically cleaned $(45 \mathrm{~W}$, for $4 \mathrm{~s}$ with an interval of $8 \mathrm{~s}$ and repeated 40 times) and collected. All the processes were repeated 15 times. The purified magnetosomes were finally dried using a vacuum freeze-drying method (Kinetics, EZ550Q) and kept at $105{ }^{\circ} \mathrm{C}$ for $24 \mathrm{~h}$ and weighed. The purified magnetosomes were sterilized by Co60 irradiation $(15 \mathrm{kGy})$ and resuspended in $0.1 \mathrm{M}$ of PBS (pH 7.4) at a concentration of $500 \mu \mathrm{g} / \mathrm{mL}^{[26]}$.

\section{Isolation of nonmagnetic subcellular fractions}

After separation of magnetosomes, an aliquot of the cell extract was subjected to ultracentrifugation $\left(330,000 \times \mathrm{g}\right.$, at $\left.4^{\circ} \mathrm{C}, 1 \mathrm{~h}\right)$. The supernatant contained the soluble proteins, and the pellet contained membrane fraction that was further separated by isopycnic centrifugation as described by Osborn and Munson $^{[27]}$.

\section{Iron concentration}

Iron concentration was measured by an atomic absorption spectrometer (Model Z8000; Hitachi, Japan) using an acetylene/air flame, as described previously by Heyen and Schüler ${ }^{[28]}$.

\section{Transmission electron microscopy (TEM)}

Bacterial cells in the pellet were rinsed three times, suspended in distilled water, adsorbed onto a 300-mesh carbon-coated copper grid and viewed directly by a transmission electron microscope (Philips Tecnai F 30, FEI Company, USA) at an accelerating voltage of 300 $\mathrm{kv}$ for recording magnetosomes.

\section{Measuring of magnetosome yields}

The magnetosome yield in bacterial cell was determined by four different approaches as: (1) counting the magnetosome numbers in at least 50 bacterial cells in TEM pictures, (2) measurement of the total magnetosome weight extracted directly from the bacterial cell culture, (3) indirect measurement of 
magnetic response of magnetosomes in each bacteria cell, and (4) measurement of intracellular iron uptake as explained above.

\section{Statistical analysis}

The data were statistically evaluated using ANOVA at the significance level of $p<0.05$ using GraphPad Prism software (v 7.01).

\section{RESULTS}

To achieve a high yield of magnetosome by $M$. gryphiswaldense strain MSR-1, we modified the composition of the initial culture medium using $25 \mathrm{mM}$ of sodium pyruvate instead of sodium lactate as the carbon source and electron donor, as well as using 40 $\mathrm{mM}$ of sodium nitrate instead of ammonium chloride as the nitrogen source. The medium was also contained $200 \mu \mathrm{M}$ of ferrous sulfate instead of $100 \mu \mathrm{M}$ ferric citrate as a major source of iron. As the electron acceptor, $\mathrm{O}_{2}$ concentration was kept at 5-10 ppm at all times by continuous injection. The incubation temperature was set at $30{ }^{\circ} \mathrm{C}$, and the $\mathrm{pH}$ was kept at 6.8. In all the experiments, the initial concentration of M. gryphiswaldense was $1.05 \times 10^{8} / \mathrm{ml}$.
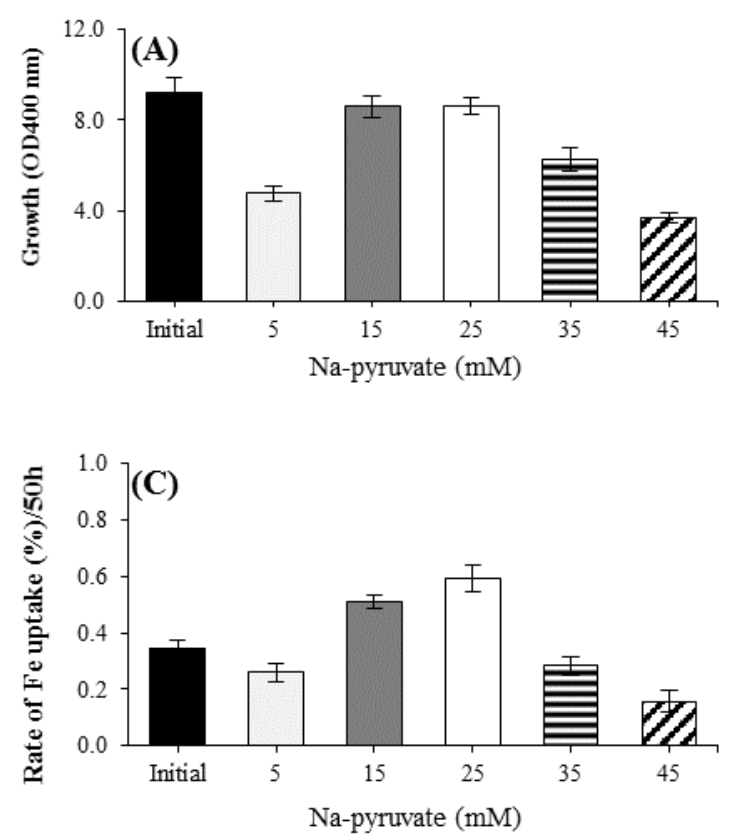

\section{Effect of oxygen concentration}

To determine the optimal oxygen concentration during the magnetosome production, three different concentrations were used. M. gryphiswaldense MSR-1 was cultured in an anaerobic condition, microaerobic condition with 5-10 ppm oxygen, and an aerobic condition in the initial medium, since most of the magnetic bacteria are often obligate microaerophiles, anaerobes, or both. Our results showed that $M$. gryphiswaldense MSR-1 had the highest growth rate in microaerobic condition, as compared to the aerobic and anaerobic conditions. A rapid increase in DO concentration from microaerobic condition with 5-10 ppm oxygen to aerobic condition in the growth conditions brought about a sharp decrease in the cellular magnetotactic response (Cmag), production of magnetosome, and reduction of Fe uptake. The results also indicated that an optimum concentration of oxygen (5-10 ppm) in microaerobic condition increased the magnetosome production significantly by $43 \%$, as well as Cmag and the rate of Fe uptake significantly increased by $28 \%$ and $39 \%$, respectively (Fig. 1B, 1C, and 1D). No significant correlation was observed between the concentration of the oxygen and growth of the magnetic bacteria in the microaerobic and anaerobic conditions. Growing
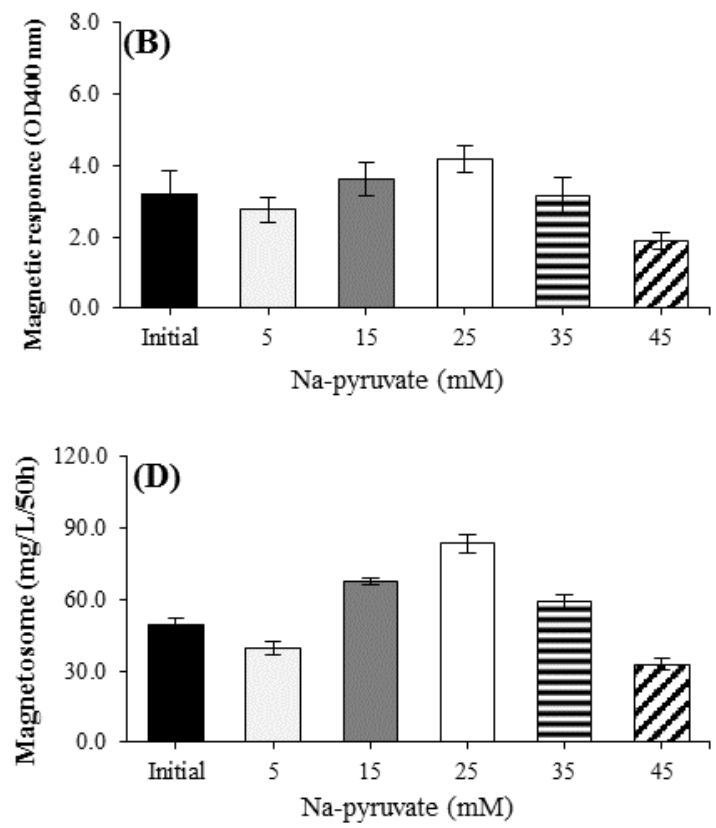

Fig. 1. Effects of dissolved oxygen (DO) concentration on factors affecting miagnctosome production by M. gryphiswaldense MSR1 during culture in optimized flask medium (OFM; 50 h). (A) Cell growth, (B) Cmag, (C) iron uptake, and (D) the magnetosome production. The maximum rates of cell growth, $\mathrm{Cmag}$, iron uptake, and magnetosome were produced under microaerobic condition (5$10 \mathrm{ppm} \mathrm{O}_{2}$ ). The optimal DO concentration was 5-10 $\mathrm{ppb}_{2}$ (microaerobic) for producing the highest quantity of magnetosome; magnetosome was produced approximately two times more than initial medium (D) $(p<0.01)$. OFM was used as an initial culture medium. 

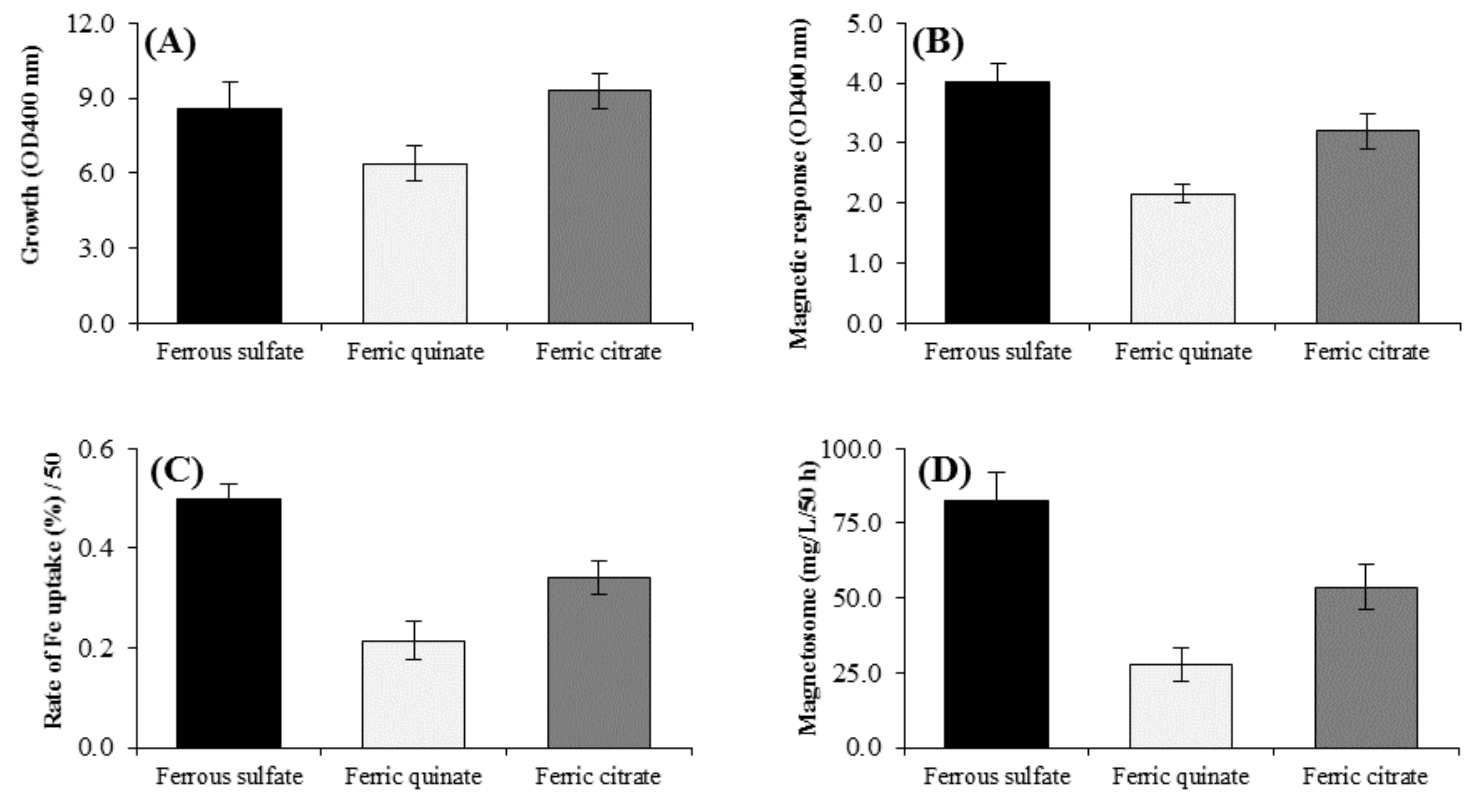

Fig. 2. Effect of different iron sources on factors affecting magnetosome production of $M$. gryphiswaldense MSR-1 during culture in optimized flask medium (OFM); 50 h). (A) Cell growth, (B) Cmag, (C) iron uptake, and (D) the magnetosome production. The maximum Cmag, iron uptake, and magnetosome production was obtained in the presence of $100 \mu \mathrm{M}$ of ferrous sulfate versus the other iron sources. The highest amount of magnetosome was produced in the presence of the ferrous sulfate, which was higher by $79 \%$ and $35 \%$, respectively as compared with ferric quinate and ferric citrate (D) $(p<0.05)$. It is notable that ferrous sulfate and ferric citrate as iron sources showed no significant effect on cell growth (A).

M. gryphiswaldense MSR-1 in a growth medium containing $15 \mathrm{mM}$ of sodium lactate as the carbon source, $20 \mathrm{mM}$ of $\mathrm{NH}_{4} \mathrm{Cl}$ sodium lactate as the carbon source, $20 \mathrm{mM}$ of $\mathrm{NH}_{4} \mathrm{Cl}$ as the nitrogen source, and $100 \mu \mathrm{M}$ of ferric citrate as the iron source at $30^{\circ} \mathrm{C}(\mathrm{pH}$ 6.8 ), and a microaerobic condition with $5-10 \mathrm{ppm}$ oxygen resulted in the highest magnetosome yield of $84.23 \mathrm{mg} / \mathrm{L}$, a significant $\mathrm{Fe}$ uptake of $0.58 \%$, and the cellular magnetotactic response at 4.26 (Fig. 1B-D). The magnetosome formation was very sensitive to the changes of the oxygen concentration. The optimal concentration of DO in the culture medium was very important environmental factor and played a role in bacteriological magnetosomes and in bacterial growth (Fig. 1).

\section{Effect of different sources of iron}

In order to obtain the optimal iron conditions for the high yield of magnetosome production, the experiments were performed and analyzed in the presence of $100 \mu \mathrm{M}$ of three different iron sources such as ferric quinate, ferrous sulfate, and ferric citrate separately in the initial medium.

\section{The effects of iron sources on magnetosome production}

The effects of ferrous sulfate on the cell growth, magnetic response, rate of $\mathrm{Fe}$ uptake, and magnetosome yield were compared with other sources of iron such as ferric citrate and ferric quinate in the presence of optimal oxygen concentration. As Figure 2 shows, the cell growth was significantly higher in the presence of ferrous sulfate or ferric citrate as compared with ferric quinate (Fig. 2A), whereas there was no significant difference between ferrous sulfate and ferric citrate. However, ferrous sulfate was significantly superior in increasing the magnetic response and magnetosome production as compared with ferric citrate (by 35\%) and ferric quinate (by 70\%), as represented in Fig. 2C and 2D. The rate of Fe uptake was significantly higher in the presence of ferrous sulfate as compared with two other sources of iron in the medium (Fig. 2B).

\section{Effects of ferrous sulfate concentrations on magnetosome production}

Cells were cultured in the presence of $5,50,100$, 150,200 , and $300 \mu \mathrm{M}$ of ferrous sulfate for 50 hours (Fig. 3). At the concentration of $200 \mu \mathrm{M}$ (111.34 $\mathrm{mg} / \mathrm{L}$ ), both the Fe uptake (as compared to the initial condition of ferric citrate) and the Cmag level increased significantly by $55 \%$ and $63 \%$, respectively (Fig. 3B-D), whereas, no significant cell growth was found at this concentration (Fig. 3A). Meanwhile, at lower concentrations of ferrous sulfate $(5-100 \mu \mathrm{M})$, the growth rate of $M$. gryphiswaldense MSR-1 increased 

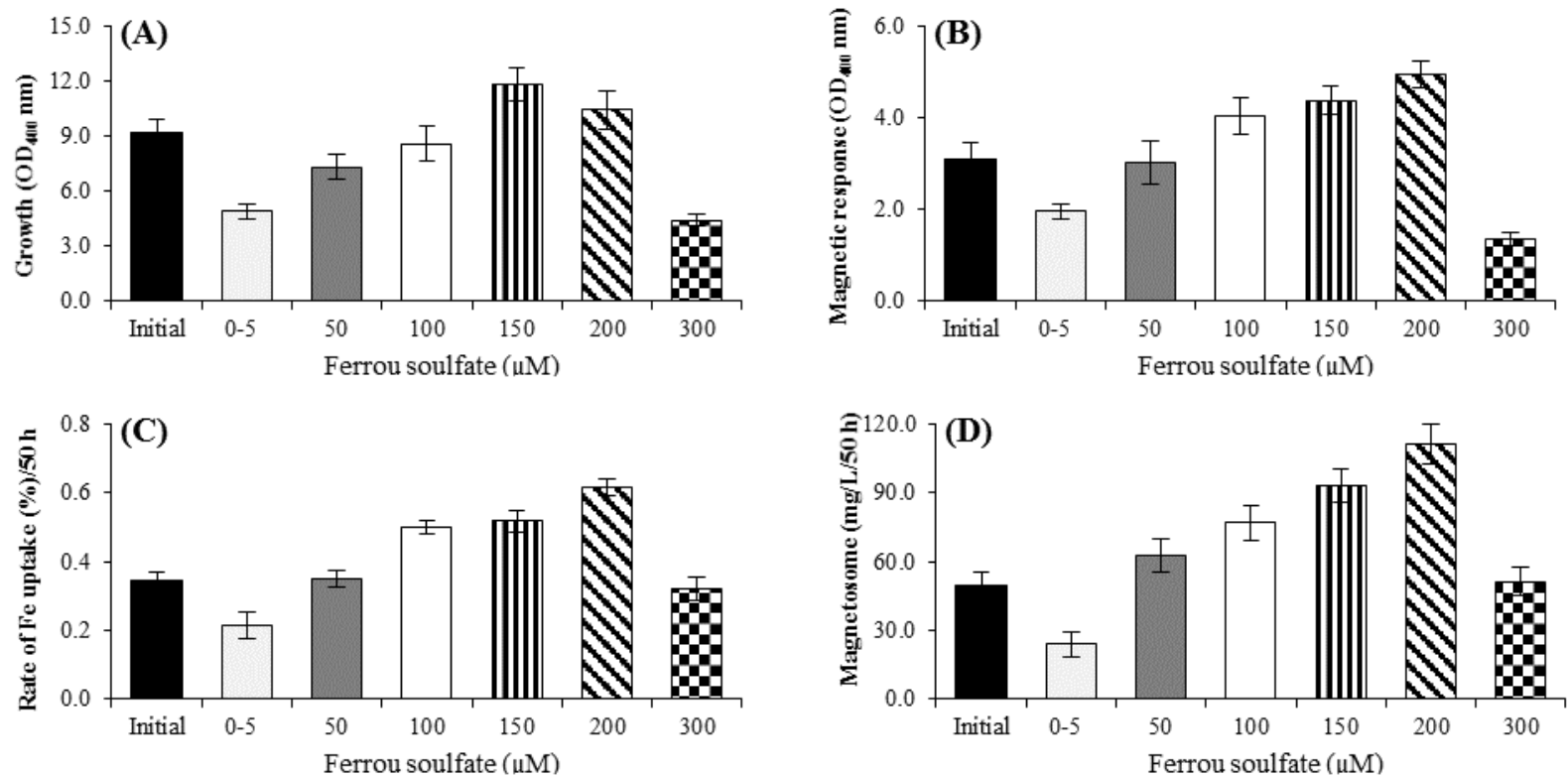

Fig. 3. Effect of different concentrations of ferrous sulfate on the factors affecting magnetosome production by M. gryphiswaldense MSR-1 during culture in optimized flask medium (OFM; 50 h). (A) Cell growth, (B) Cmag, (C) iron uptake, and (D) the magnetosome production. The maximum rate of cell growth in the concentration of $150 \mu \mathrm{M}(\mathrm{A})$ and the maximum rates of Cmag, iron uptake, and magnetosome production were obtained in the presence of $200 \mu \mathrm{M}$ ferrous sulfate $(\mathrm{B}, \mathrm{C}$, and D). The optimum concentration of ferrous sulfate for the highest magnetosome production yield was determined to be 150 to $200 \mu \mathrm{M}$. At these concentrations, the magnetosome production was $62 \%$ more than the initial condition (D) $(p<0.01)$.

significantly $(p<0.05$; Fig. 3A). When the ferrous sulfate concentration was over $200 \mu \mathrm{M}$, a significant decrease was observed in bacteria cell growth. Ferrous sulfate is believed to be essential for the synthesis of magnetosomes (Fig. 3A).

\section{Effects of different sources of carbon}

Four different common carbon sources, including sodium pyruvate sodium L-lactate, sodium acetate, and sodium succinate, were investigated in the culture medium (data not show). Sodium pyruvate and sodium L-lactate increased the cell growth, the cellular magnetotactic response (Cmag), the rate of Fe uptake, and magnetosome production significantly, as compared with sodium succinate and sodium acetate (data not show). The results also revealed that sodium pyruvate was even more effective on increasing the magnetosome production (data not shown).

\section{Effects of different concentrations of sodium pyruvate}

Five different concentrations of sodium pyruvate in the range of $5,15,25,35$, and $45 \mathrm{mM}$ were investigated (Fig. 4). As the sodium pyruvate concentration increased from 5 to $15 \mathrm{mM}$, the cell growth increased up to $45 \%$. Also, a significant increase was observed in $\mathrm{Cmag}$, the rate of $\mathrm{Fe}$ uptake, and magnetosome production (Fig. 4B-D, respectively). However, when the concentration exceeded over $15 \mathrm{mM}$, the cell growth no longer increased (Fig. 4A). It should be noted that the maximum magnetosome production value was found to be $93.5 \mathrm{mg} / \mathrm{L}$ at $50 \mathrm{~h}$ when the sodium pyruvate concentration was $25 \mathrm{mM}$ in OFM, which increased $67 \%$ in comparison to the control condition (Fig. 4D).

\section{Effects of different sources of nitrogen}

Three common nitrogen sources recommended in most of the culture media include $\mathrm{NaNO}_{3},\left(\mathrm{NH}_{4}\right)_{2} \mathrm{SO}_{4}$, and $\mathrm{NH}_{4} \mathrm{Cl}$ with the concentration of $20 \mathrm{mM}$ in OFM (data not shown). The results showed that $\mathrm{NaNO}_{3}$ increased the cellular magnetotactic response (Cmag), the rate of $\mathrm{Fe}$ uptake, and magnetosome production significantly, as compared to $\mathrm{NH}_{4} \mathrm{Cl}$ and $\left(\mathrm{NH}_{4}\right)_{2} \mathrm{SO}_{4}$ (data not show). The maximum rate of growth was seen in the presence of $\mathrm{NH}_{4} \mathrm{Cl}$ (data not show). The influence of different concentrations of $\mathrm{NaNO}_{3}(20,40$, 60 , and $80 \mathrm{mM}$ ) on growth and magnetosome formation was investigated. By increasing the $\mathrm{NaNO}_{3}$ concentration from 20 to $60 \mathrm{mM}$, the growth rate increased by $27 \%$, while the Cmag, the rate of iron uptake, and the magnetosome production decreased (Fig. 5). At the concentration above $60 \mathrm{mM}$, no significant changes was observed in the growth rate. At $40 \mathrm{mM}$, the magnetosome production increased 38\% (79.99 mg/L in 50 h; Fig. 5D). 

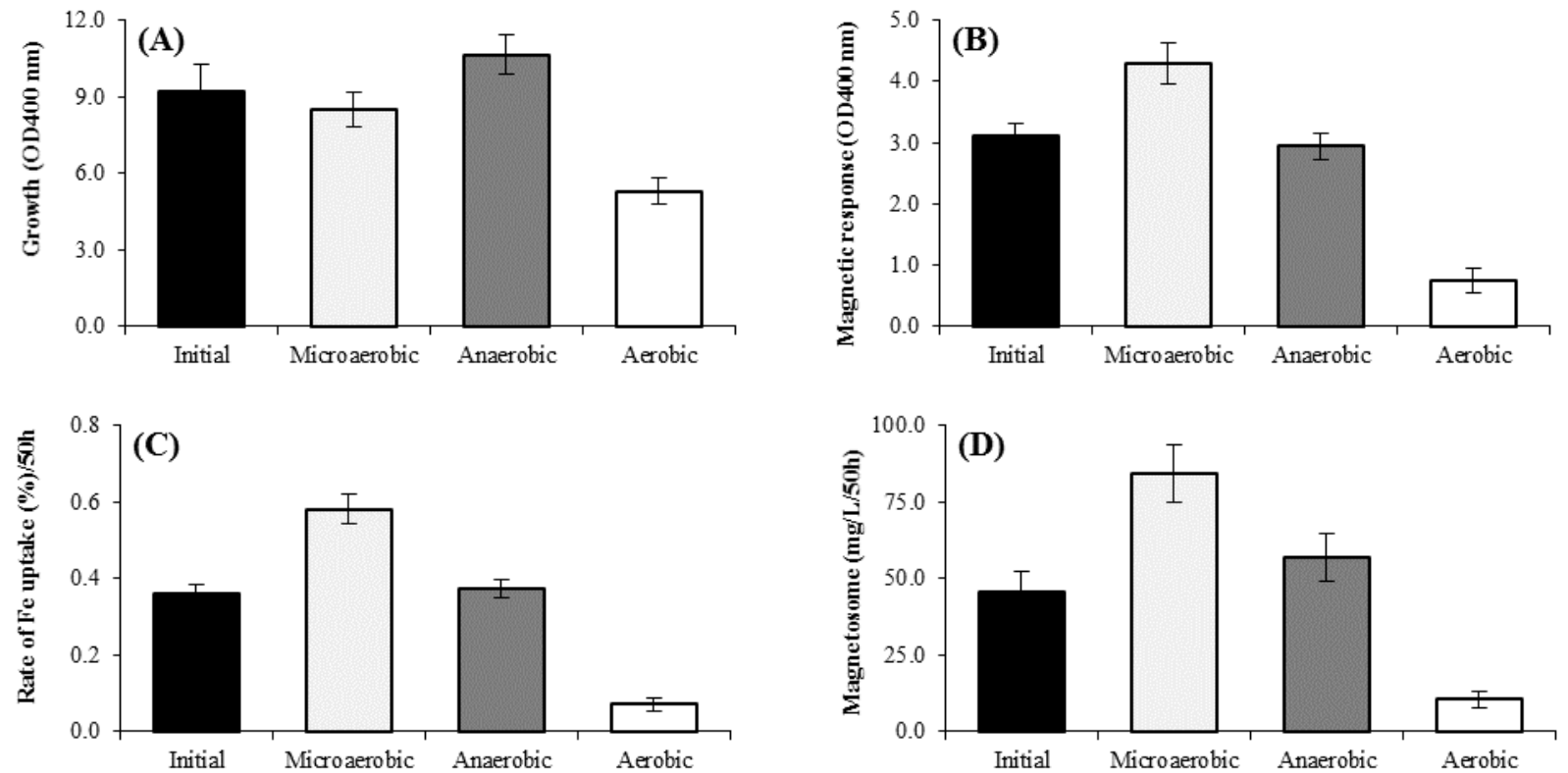

Fig. 4. Effect of different concentrations of Na-pyruvate on factors affecting the magnetosome production of M. gryphiswaldense MSR-1 during culture in optimized flask medium (OFM; 50 h). (A) Cell growth, (B) Cmag, (C) iron uptake, and (D) the magnetosome production. There was no significant difference in the cell growth at the concentration of 15 and $25 \mathrm{mM}$ of Na pyruvate as compared to the initial condition (A). The Cmag, iron uptake, and magnetosome produced at the concentration of $25 \mathrm{mM}$ of Na pyruvate. Under the optimal concentration of $\mathrm{Na}$ pyruvate $(\sim 25 \mathrm{mM})$, the amount of magnetosome was $67 \%$, which was much more than the initial condition (D) $(p<0.01)$.

\section{Optimized conditions for cell growth and} magnetosome production

The growth of $M$. gryphiswaldense MSR-1 under different conditions of the types and amounts of iron, nitrogen, and carbon sources and oxygen concentration is shown in Figure 6. The optimized culture medium, contained $25 \mathrm{mM}$ of sodium pyruvate, $40 \mathrm{mM}$ of $\mathrm{NaNO}_{3}, 200 \mu \mathrm{M}$ of ferrous sulfate, and 5-10 ppm of $\mathrm{O}_{2}$ concentration. The highest magnetosome production was about $186.87 \mathrm{mg} / \mathrm{L} / 50 \mathrm{~h}$ (Fig. 6).

\section{Tranmission electron microscopy of magnetosom}

In order to prove the high level of magnetosome production in the optimized conditions and initial in 50 h, TEM was performed (Fig. 7).

\section{DISCUSSION}

In this report, we attempted to increase the production of magnetosome in MSR-1 strain of $M$. gryphiswaldense by optimizing the supply of oxygen, iron, carbon, and nitrogen. The results showed that the oxygen has a critical role in the synthesis of magnetosomes. At DO level above 5-10 ppm, the iron uptake and magnetosome production reduced, but the bacterial growth was normal. However, at lower DO $(<5-10 \mathrm{ppm})$, the rate of iron uptake, Cmag, and magnetosome production increased that is likely associated with the slow growth of bacteria. These observations are in agreement with those reported by Yang et $a{ }^{[13]}$. It has also been reported that magnetosome yield could be significantly increased under microaerobic conditions; however, the exact role of oxygen in magnetosome biomineralization is still unclear $^{[1]}$. Most reports have claimed that oxygen is necessary to maintain the required redox potential for magnetosome growth ${ }^{[12,28]}$. M. gryphiswaldense MSR1 is facultative anaerobic bacteria with aerobic condition preference for the cell growth ${ }^{[13]}$. During magnetotactic bacteria growth the concentration of $\mathrm{O}_{2}$ had a specific effect on the synthesis of magnetosomes. It increases the magnetosome production at concentrations lower than 5-10 ppm, whereas at higher concentrations, it decreases the magnetosomes ${ }^{[4,29,30]}$. Therefore, controlling DO level in the culture medium or altering aerobic/anaerobic conditions is favorable for magnetosome production ${ }^{[4,25,31-33]}$.

In addition to oxygen levels, our study showed that the iron source is another important factor for more efficient uptake of this vital ion and the magnetosome production. Ferrous sulfate was better source of iron for $M$. gryphiswaldense than ferric quinate and citrate, perhaps because the reduced form of ferrous is more soluble compared to the oxidized analogue. This result is in line with the findings of Yang et al. ${ }^{[24]}$. 

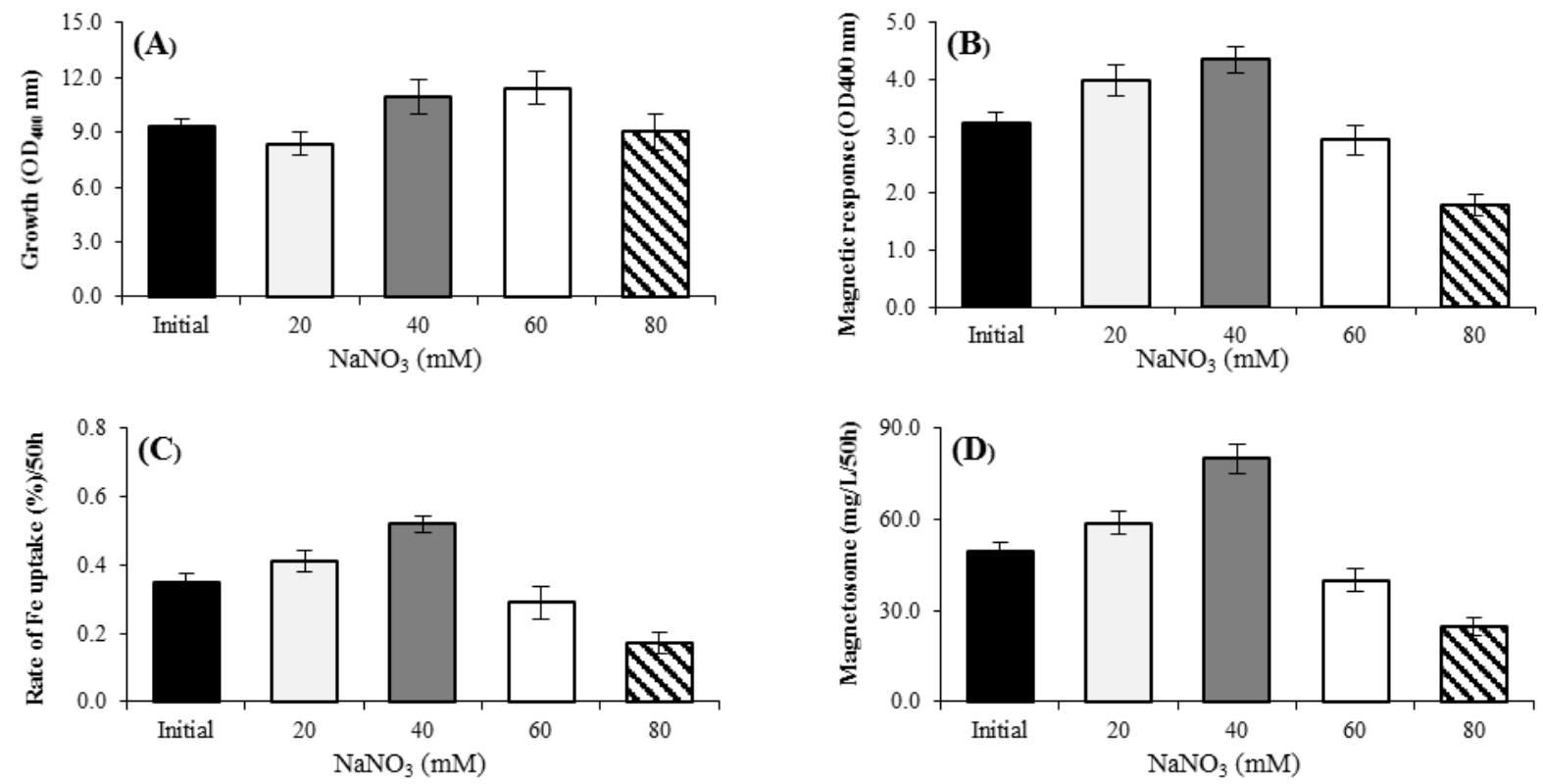

Fig. 5. Effect of $\mathrm{NaNO}_{3}$ concentrations on magnetosome production in optimized flask medium (OFM; 50 h). (A) Cell growth, (B) Cmag, (C) iron uptake, and (D) the magnetosome production. The maximum cell growth was observed in the concentration of $60 \mathrm{mM}$ $\mathrm{NaNO}_{3}(\mathrm{~A})$, and the maximum production of Cmag, iron uptake, and magnetosome was under the concentration of $40 \mathrm{Mm} \mathrm{NaNO}_{3}(\mathrm{~B}$, $\mathrm{C}$, and D) in OFM. The optimal concentration of $\mathrm{NaNO}_{3}$ was determined to be $40 \mathrm{mM}$ for the highest magnetosome production yield, which showed $38 \%$ more magnetosome production than the initial condition (D) $(p<0.01)$.

We showed that the excess concentrations of iron in the culture medium can be toxic for $M$. gryphiswaldense MSR-1. A slight increase in extracellular iron concentration elevated the iron uptake, magnetosome production, Cmag, and cell growth, but the ferrous sulfate concentration above 150 $\mu \mathrm{M}$ led to reduction in the cell growth and enhancement of the iron uptake rate, Cmag, and magnetosome production. Iron concentrations $\geq 300$ $\mu \mathrm{M}$ could damage the bacteria seriously and significantly reduce the rate of iron uptake, Cmag, magnetosome production, and the growth rate (Fig. 3). In magnetotactic bacteria, iron not only acts as a protein cofactor but also accelerates the biomineralization process in the cells ${ }^{[6,14,29]}$. It has been demonstrated by Faivre et al. ${ }^{[29]}$ that $M$. gryphiswaldense utilizes soluble ferrous ions and ferric (ferritin form) synchronously for the magnetosome production. Maximum magnetosome production was observed at $200 \mu \mathrm{M}$ of iron, which was in agreement with the reported results ${ }^{[34-36]}$. Using TEM analysis, we proved that in the optimized culture medium, both the quantity and size of magnetosome increased (Fig. 7). This observation was also noted by Liu et al. ${ }^{[12]}$. Furthermore, the increased number of double chains in bacteria indicates the optimal medium is an appropriate condition for the growth of $M$. gryphiswaldense (Fig. 7).
Our results confirmed the superiority of pyruvate and lactate for magnetosome production over acetate and succinate as reported previously ${ }^{[12,28]}$. This preference may indicate that pyruvate and lactate have better redox potential in comparison with succinate and acetate as the electron donor for ATP synthesis ${ }^{[37]}$. We showed that $25 \mathrm{mM}$ sodium pyruvate was the optimal concentration for magnetosome production by Magnetospirillum sp., as reported also by Liu et al. ${ }^{[12]}$ and Zhang et al. ${ }^{[22]}$. They concluded that such behavior can be related to the bacterial susceptibility to increased osmotic potential ${ }^{[22]}$. For magnetosome synthesis, the role of nitrogen is very important to form proteins for the assembly of magnetosome and to transport and incorporate iron in the magnetotactic bacteria. Our data showed that in the magnetotactic bacteria, the use of $\mathrm{NaNO}_{3}$, as a nitrogen source, leads to more magnetosome production versus using $\mathrm{NH}_{4} \mathrm{Cl}$ and $\left(\mathrm{NH}_{4}\right)_{2} \mathrm{SO}_{4}$. This result contradicts the results of Liu et al. ${ }^{[12]}$. Nitrate is a strong oxygen acceptor having redox potential, which supports our observations (Fig. 6). The culture medium containing the low concentration of nutrients (in particular carbon and nitrogen) is a key limiting factor that affects magnetosome production and cell density of all magnetotactic bacteria. Our results showed that in magnetosome synthesis, the rate of iron uptake and Cmag enhanced at lower concentrations of $\mathrm{NaNO}_{3}(40$ 

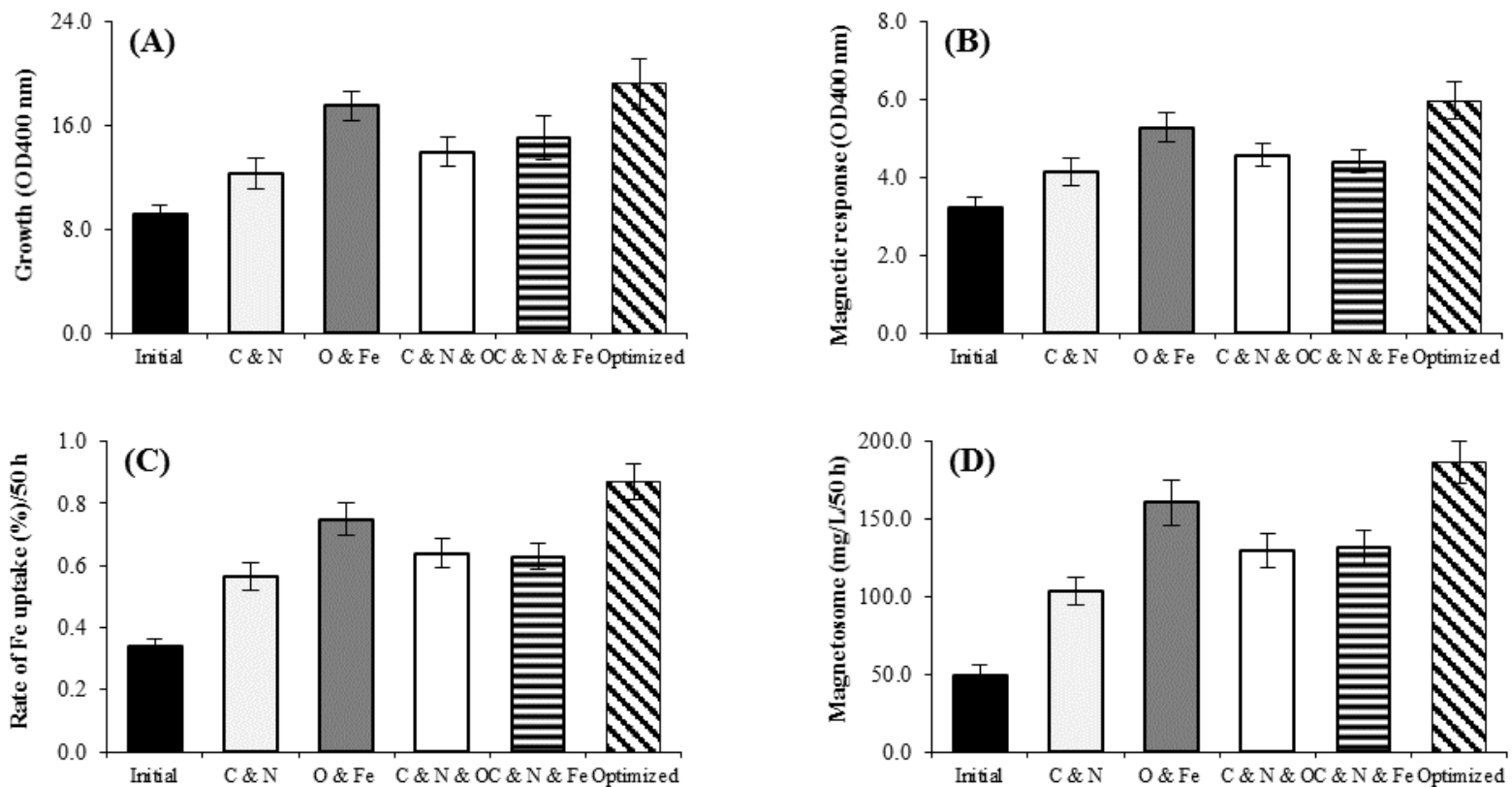

Fig. 6. The growth of M. gryphiswaldense MSR-1 under different conditions of the types and amounts of iron, nitrogen, and carbon sources and oxygen concentration. The maximum rate of cell growth in the optimized conditions (A), the maximum rate of Cmag, iron uptake, and magnetosome production under optimized oxygen and iron concentration (B, C, and D), respectively. The highest amount of magnetosome was achieved at the optimized condition including optimized oxygen and iron concentrations when magnetosome production was $75 \%$ and $64 \%$, respectively (D) $(p<0.01)$.

$\mathrm{mM})$, as compared to the higher concentrations $(60$ $\mathrm{mM}$ ), which support previous results ${ }^{[38]}$. Proteins promote the nucleation of iron crystals, leading to magnetosome production in magnetotactic bacteria after the vesicles assembling ${ }^{[39]}$. It has recently been illustrated that the magnetosome-associated membrane proteins play a significant role in magnetosome crystals growth inside the magnetotactic bacteria ${ }^{[39,40]}$. Our result showed that within 50-h culture, a maximum amount of magnetosome was produced (about 186.87 $\mathrm{mg} \mathrm{L}^{-1}$ ), and $5.76 \mathrm{~g} \mathrm{~L}^{-1}$ bacterial cells were obtained, whereas the cell growth rate was $2.768 \mathrm{~g} \mathrm{~L}^{-1}$ /day.

The magnetic nanoparticles are synthesized in the presence of low oxygen and high level of iron concentrations under the influence of intracellular microbial reduction as trivalent iron compounds ${ }^{[4,41]}$. The numbers and shapes of the magnetosomes vary depending on the conditions of the culture medium, in particular, the concentration of available soluble iron, $\mathrm{DO}$, nutrients, temperature, $\mathrm{pH}$, and degradation power. On average, between 10 and 30 magnetosomes are synthesized in each bacterial cell.
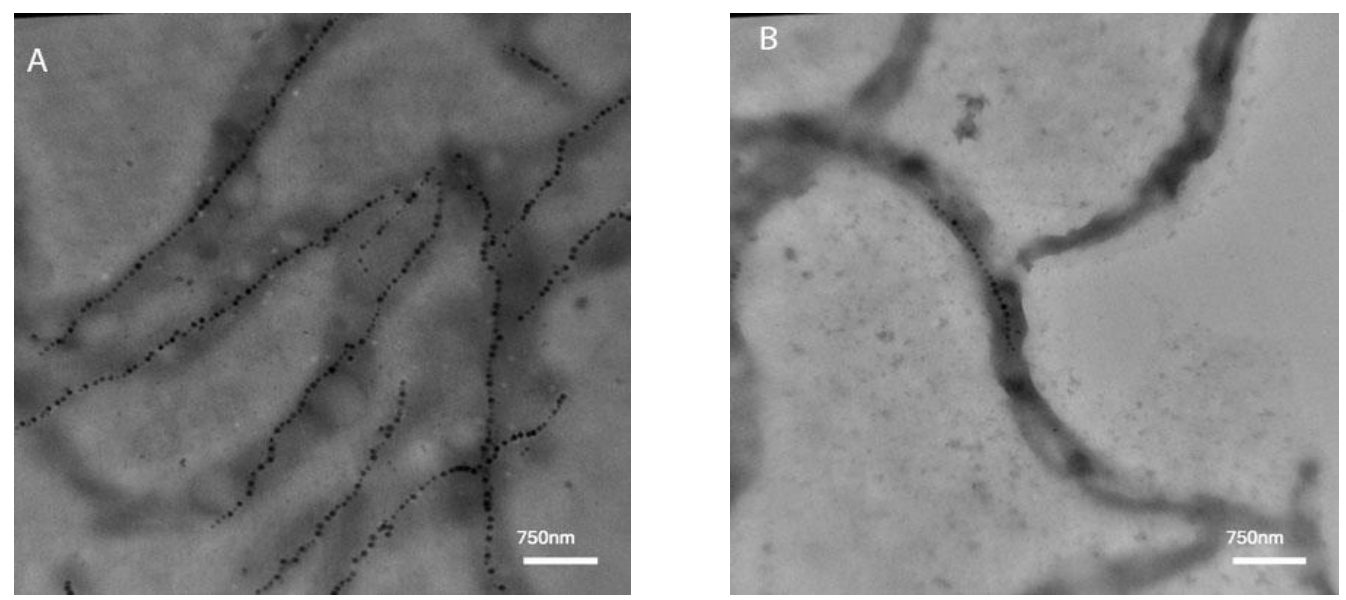

Fig. 7. Transmission electron microscopy image of magnetosome chains of $M$. gryphiswaldense MSR-1. (A) Under the optimized culture medium, and (B) under the initial culture medium. 
For the synthesis of magnetosomes, the bacterial cells need to uptake a large amount of iron from its surroundings and put in the bio-mineralization process $^{[11,38]}$. Also, these crystals are required to be in well-defined numbers, shapes, and crystal size, in order to play an efficient magnetic field sensor role. The composition of additives in culture medium can have significant effects on the size and other magnetic properties of these nanoparticles ${ }^{[28]}$.

In summary, we report an improved MSR-1 culture medium condition for increased magnetosome yield, magnetosome number per cell, magnetic resonance, and cell yield in a shorter time and the reduced cost. Our method allows achieving the mass production of magnetosomes by MSR-1 in a fermentor scale by choosing the suitable sources and concentrations of culture medium composition. The most important advantages of this protocol are: (1) the concentrations of oxygen, iron, carbon, and nitrogen sources in the medium can be auto-controlled at a constant level by $\mathrm{pH}$-stat feeding, leading to ease of manipulation and elimination of the possibility of nutrient exhaustion during the culture process and (2) easy up-scale process for industrial production without need for genetic manipulation. The DO and iron are the major factors affecting the magnetosome production in the bacterial culture. Further refinements of this protocol to overcome other shortages of the magnetosome production of magnetotactic bacteria are ongoing in our laboratory.

\section{ACKNOWLEDGEMENTS}

This work was supported and funded by the Department of Research and Development at Pasteur Institute of Iran as a student project.

CONFLICT OF INTEREST. None declared.

\section{REFERENCES}

1. Arakaki A, Nakazawa $\mathrm{H}$, Nemoto $\mathrm{M}$, Mori $\mathrm{T}$, Matsunaga T. Formation of magnetite by bacteria and its application. Journal of royal society interface 2008; 5: 977-999.

2. Bazylinski D, Lefèvre CT, Lower BH. Magnetotactic bacteria, magnetosomes, and nanotechnology. Nanomicrobiology: physiological and environmental characteristics 2014 ; 39-74.

3. Faivre D, Schüler D. Magnetotactic bacteria and magnetosomes. Chemical reviewes 2008; 108(11): 4875-4898.

4. Moisescu C, Ardelean II, Benning LG. The effect and role of environmental conditions on magnetosome synthesis. Frontiers in microbiology 2014; 5: 49.

5. Iravani S. Bacteria in nanoparticle synthesis: current status and future prospects. International scholarly research notices 2014; 2014:359316.

6. Bazylinski DA, Frankel RB. Biologically Controlled Mineralization of Magnetic Iron Minerals by Magnetotactic Bacteria. American Society of Microbiology Publishing; 2000. p.109-144.

7. Blakemore R. Magnetotactic bacteria. Science 1975; 190(4212): 377-379.

8. Yan L, Da H, Zhang S, López VM, Wang W. Bacterial magnetosome and its potential application. Microbiology research 2017; 203:19-28.

9. Alphandéry E. Applications of magnetosomes synthesized by magnetotactic bacteria in medicine. Frontiers in bioengineering and biotechnology 2014; 2: 5.

10. Sun JB, Zhao F, Tang T, Jiang W, Tian JS, Li Y, Li JL. High-yield growth and magnetosome formation by Magnetospirillum gryphiswaldense MSR-1 in an oxygen-controlled fermentor supplied solely with air. Applied microbiology and biotechnology 2008; 79(3): 389-397.

11. Ali I, Peng C, Khan ZM, Naz I. Yield cultivation of magnetotactic bacteria and magnetosomes: A review. Journal of basic microbiology 2017; 57(8): 643-652.

12. Liu Y, Li GR, Guo FF, Jiang W, Li Y, Li L. Large-scale production of magnetosomes by chemostat culture of Magnetospirillum gryphiswaldense at high cell density. Microbial cell factories 2010; 9: 99.

13. Yang J, Li S, Huang X, Tang T, Jiang W, Zhang T, Li Y. A key time point for cell growth and magnetosome synthesis of Magnetospirillum gryphiswaldense based on real-time analysis of physiological factors. Frontiers in microbiology 2013; 4: 210.

14. Araujo AC V, Abreu F, Silva KT, Bazylinski DA, Lins U. Magnetotactic bacteria as potential sources of bioproducts. Marine drugs 2015; 13(1): 389-430.

15. Hopkin M. Magnet-making bacteria could target tumours. Nature 2004; doi:10.1038/news040906-11.

16. Shao $\mathrm{H}$, Min $\mathrm{C}$, Issadore $\mathrm{D}$, Liong $\mathrm{M}$, Yoon $\mathrm{TJ}$, Weissleder R, Lee H. Magnetic nanoparticles and microNMR for diagnostic applications. Theranostics 2012; 2(1): 55-65.

17. Sun C, Lee JS, Zhang M. Magnetic nanoparticles in MR imaging and drug delivery. Advanced drug delivery reviews 2008; 60(11): 1252-1265.

18. Wahajuddin, Arora S. Superparamagnetic iron oxide nanoparticles: magnetic nanoplatforms as drug carriers. International journal of nanomedicine 2012; 7: 34453471.

19. Sun J, Li Y, Liang XJ, Wang PC. Bacterial magnetosome: a novel biogenetic magnetic targeted drug carrier with potential multifunctions. Journal of nanomaterial 2011; 2011: Article ID 469031.

20. Takeyama H, Yamazawa A, Nakamura C, Tadashi M. Application of bacterial magnetic particles as novel DNA carrier for ballistic transformation of a marine cyanobacterium. Biotechnology techniques 1995; 9: $355-360$ 
21. Nakamura $\mathrm{N}$, Hashimoto $\mathrm{K}$, Matsunaga $\mathrm{T}$. Immunoassay method for the determination of immunoglobulin $\mathrm{G}$ using bacterial magnetic particles. Analytical chemistry 1991; 63: 268-272.

22. Zhang $Y$, Zhang $X$, Jiang $\mathrm{W}$, Li Ym Li J. Semicontinuous culture of Magnetospirillum gryphiswaldense MSR-1 cells in an autofermentor by nutrient-balanced and isosmotic feeding strategies. Applied and environmental microbiology 2011; 77(17): 5851-5856.

23. Wang Q, Wang X, Zhang W, Li X, Zhou Y, Li D, Wang Y, Tian J, Jiang W, Zhang Z, Peng Y, Wang L, Li Y, Li J. Physiological characteristics of Magnetospirillum gryphiswaldense MSR-1 that control cell growth under high-iron and low-oxygen conditions. Nature 2017; Article number: 2800.

24. Yang C, Takeyama H, Matsunaga T. Iron feeding optimization and plasmid stability in production of recombinant bacterial magnetic particles by Magnetospirillum magneticum AMB-1 in fed-batch culture. Journal of bioscience and bioengineering 2001; 91: 213-216.

25. Schüler D, Baeuerlein E. Dynamics of iron uptake and $\mathrm{Fe}_{3} \mathrm{O}_{4}$ biomineralization during aerobic and microaerobic growth of Magnetospirillum gryphiswaldense. Journal of bacteriology 1998; 180: 159-162.

26. Grünberg K, Wawer C, Tebo BM, Schüler D. A large gene cluster encoding several magnetosome proteins is conserved in different species of magnetotactic bacteria. Applied and environmental microbiology 2001; 67: 4573-4582.

27. Osborn MJ, Munson R. Separation of the Inner (Cytoplasmic) and Outer Membranes of Gram-negative Bacteria. Elsevier Publishing; 1974. p. 642-653.

28. Heyen U, Schüler D. Growth and magnetosome formation by microaerophilic Magnetospirillum strains in an oxygen-controlled fermentor. Applied microbiology and biotechnology 2003; 61(5-6): 536544.

29. Faivre D, Menguy N, Pósfai M, Schüler D. Environmental parameters affect the physical properties of fast-growing magnetosomes. Americal mineralogist 2008; 93(2-33): 463-469.

30. Yan L, Zhang S, Chen P, et al. Magnetotactic bacteria, magnetosomes and their application. Microbiological research 2012; 167(9): 507-519.

31. Calugay RJ, Miyashita H, Okamura Y, Matsunaga T. Siderophore production by the magnetic bacterium Magnetospirillum magneticum AMB-1. FEMS microbiology letters 2003; 218(2): 371-375.

32. Amor M, Busigny V, Durand-Dubief M, Tharaud M,
Ona-Nguema G, Gélabert A, Alphandéry E, Menguy N, Benedetti MF, Chebbi I, Guyot F. Chemical signature of magnetotactic bacteria. Proceedings of the national academy of sciences of the United States of America 2015; 112: 1699-1703.

33. Liu RT, Liu J, Tong JQ, Tnag T, Chaokong W, wenWang $\mathrm{X}$, Li Y, Tang JT. Heating effect and biocompatibility of bacterial magnetosomes as potential materials used in magnetic fluid hyperthermia. Progress in national science: material international 2012; 22(1): 31-39.

34. Rong C, Zhang C, Zhang Y, Qi L, Yang J, Guan G, Li $\mathrm{Y}, \mathrm{Li}$ J. FeoB2 functions in magnetosome formation and oxidative stress protection in Magnetospirillum gryphiswaldense strain MSR-1. Journal of bacteriology 2012; 194(15): 3972-3976.

35. Singh AK, Srivastava ON, Singh K. Shape and sizedependent magnetic properties of $\mathrm{Fe}_{3} \mathrm{O}_{4}$ nanoparticles synthesized using piperidine. Nanoscale research letters 2017; 12: 298.

36. Zhang S, Yan L, Li H, Liu H. Optimal conditions for growth and magnetosome formation of Acidithiobacillus ferrooxidans. African journal of microbiology reserch 2012; 6(32): 6142-6151.

37. Kane AL, Brutinel ED, Joo H, MAysonet R, VanDrisee CM, Kotloski NJ, Gralnick JA. Formate metabolism in Shewanella oneidensis generates proton motive force and prevents growth without an electron acceptor. Journal of bacteriology 2016; 198(8): 1337-1346.

38. Naresh M, Das S, Mishra P, Mittal A. The chemical formula of a magnetotactic bacterium. Biotechnology and bioengineering 2012; 109(5): 1205-1216.

39. Lopez-Moreno R, Fernández-Vivas A, ValverdeTercedor C, Azuaga Fortes AI, Casares Atienza S, Rodriguez-Navarro A, Zarivach R, Jimenez-Lopez C. Magnetite nanoparticles biomineralization in the presence of the magnetosome membrane protein MamC: Effect of protein aggregation and protein structure on magnetite formation. Crystal growth design 2017; 17(4): 1620-1629.

40. Lefèvre CT, Bazylinski DA. Ecology, diversity, and evolution of magnetotactic bacteria. Microbiology and molecular biology reviewes 2013; 77(3): 497-526.

41. Bazylinski DA, Williams TJ, Lefèvre CT, Berg RJ, Zhang CL, Bowser SS, Dean AJ, Beveridge TJ. Magnetococcus marinus gen. nov., sp. nov., a marine, Mgnetotactic bacterium that represents a novel lineage (Magnetococcaceae fam. nov., Magnetococcales ord. nov.) at the base of the Alphaproteobacteria. International journal of systematic and evolutionary microbiology 2013; 63(Pt 3): 801-808. 